\title{
Pendidikan Karakter Berbasis Nilai Muwashafat Pada Murid Sekolah Dasar Islam Terpadu Bunayya Pekanbaru
}

\author{
Yenni Yunita*, Ismail Akzam, Rojja Pebrian \\ Universitas Islam Riau, Indonesia \\ Jl. Kaharuddin Nasution No. 113, Perhentian Marpoyan, Kota Pekanbaru, Indonesia. \\ Email: yenniyunita@fis.uir.ac.id
}

\begin{abstract}
Students character education at Bunayya Islamic elementary school Pekanbaru is in fact how the educators teach and instill Islamic good manners to students then asks them to implement in their daily life both at school environment and home by referring to 10 muwasafat, namely: pure aqidah, True worship, strong moral, strong physic, Smart in thinking, fight against lust, keeping time, organize in affairs, become autonomous, benificial to others. This is field field research with quantitative means research which uses numbers in presenting data and analysing by using statistical method. Data that used was quantitative data means data in the form of numbers that analyzed by using statistical that was taken from the observation dealing to ten muwashafat on students at Bunayya Islamic Elementary school on the basis of teachers' assessment. There are some factors that influence students' character at Bunayya Islamic Elementary school namely parents, family, friends, environment and electronic media such as internet, handphone, gadget and television program. The most important factor is ten muwashafa that owned by Students at Bunayya Islamic Elementary school.
\end{abstract}

Key words: Character Education, ten Muwashafat, Students' SDIT Bunayya

Abstrak: Pendidikan karakter murid di SDIT Bunayya Pekanbaru intinya bagaimana pendidik mengajarkan dan menanamkan nilai-nilai islami kepada peserta didik kemudian membiasakannya dalam kehidupan sehari-hari baik di lingkungan sekolah maupun di lingkungan rumah dengan mengacu kepada 10 muwassafat. Kemudian membiasakannya dalam kehidupan keseharian anak baik di rumah maupun sekolah dengan berpedoman pada 10 muwasafat, yaitu: "Salimmul Aqïdah (Aqidah yang bersih), Shahihul Ibadah (Ibadah yang benar), Matinul Khuluq (Akhlak yang kokoh), Qowiyyul Jismi (kuat jasmani), Musaqqoful Fikri (Intelek dalam berpikir), Mujahadatul Linafsihi (Berjuang Melawan hawa nafsu), Harișun 'Ala Waqtihi (Pandai menjaga waktu), Munazzamun fi Syūnihi (teratur dalam urusan), Qodirun 'Alal Kasbi (mampu berusaha sendiri atau mandiri), Nafi'un Ligoirihi (bermanfa'at bagi orang lain)". Penelitian ini termasuk penelitian lapangan (field research) yang bersifat kuantitatif, yaitu penelitian yang menggunakan angka dalam menyajikan data dan analisis yang menggunakan uji statistika. Data yang digunakan adalah data kuantitatif yaitu data yang berupa angkaangka dan analisis menggunakan statistik yang diambil dari hasil pengamatan mengenai sepuluh muwashafat pada murid sekolah Islam terpadu Al-Bunayya atas penilaian guru. Faktor yang mempengaruhi karakter murid di SDIT Bunayya Pekanbaru diantaranya orang tua, keluarga, teman, dan lingkungan serta media elektronik seperti internet, handphone, gadget, dan tayangan TV. Adapun faktor yang paling penting adalah sepuluh muwashafat yang dimiliki oleh murid sekolah dasar Islam terpadu Bunayya Pekanbaru.

Kata Kunci: Pendidikan Karakter, Sepuluh Muwashafat, Murid SDIT Bunayya

Jurnal Pendidikan Agama Islam Al-Thariqah Vol. 4, No. 2, Juli - Desember 2019

Received: 19 December 2019; Accepted: 06 March 2020; Published: 07 March 2020

*Corresponding Author: yenniyuita@fis.uir.ac.id 


\section{PENDAHULUAN}

Peletakan dasar-dasar pendidikan agama adalah kewajiban orang tua dan juga menjadi tugas guru, masyarakat, dan pemerintah melalui berbagai lembaga pendidikan. Tulisan ini membahas tentang pentingnya pendidikan Al-Quran, pendidikan berbasis Al-Quran, dan pembentukan karakter peserta didik melalui pendidikan.

Penelitian ini bertujuan untuk mengetahui Pendidikan Karakter berbasis nilai Muwashafat pada Murid Sekolah Dasar Islam Terpadu Al-Bunayya serta faktor yang mempengaruhi terbentuknya Karakter Murid di Sekolah Dasar Islam Terpadu Bunayya Pekanbaru.

Tulisan ini hendak melihat pendidikan budi pekerti untuk membentuk karakter murid di sekolah Dasar Islam masih dalam persimpangan jalan. Pengembangan karakter murid diperlukan untuk membentuk mata pelajaran budi pekerti. Pendidikan yang selama ini dialami murid di sekolah masih bersifat kognitif. Padahal, untuk dapat mewujudkan hasil didikan yang maksimal, mereka haruslah memiliki pengetahuan secara intelektual dan pendidikan budi pekerti untuk membangun karakter bangsa.

Salah satu sekolah yang menerapkan pendidikan karakter adalah SDIT Bunayya Pekanbaru terlihat dari visi sekolah ini yaitu "menjadikan sekolah dasar unggul yang mencetak sisiwa berkarakter, berpengetahuan dan terampil”.

\section{KONSEP TEORI}

Erwati dalam Aziz (2013: 7) menjelaskan bahwa "di negara-negara berkembang masalah lingkungan tidak kalah pentingnya dibandingkan dengan negara maju, namun kasus dan penyebabnya tidaklah sama. Kalau di negara-negara maju yang menjadi penyebab utamanya adalah limbahlimbah industri seperti mercuri, gas beracun, smog dsb, maka dinegara-negara berkembang seperti Indonesia adalah limbah rumah tangga dan kotoran manusia". Selanjutnya, Zakiah Darajat dalam Aziz (2013: 11) yang merupakan seorang pendidik dan ahli ilmu jiwa cendung berpendapat bahwa "penyebab kesusakan lingkungan hidup dikarenakan pendidikan Islam tidak tertanam dengan baik dan menyebabkan tidak dijalankannya ajaran agama dengan baik". Meskipun para ahli berbeda pendapat tentang sebab terjadinya kerusakan namun tidak ada yang membantah bahwa manusia adalah salah satu penyebab kerusakan alam tersebut. Bagaimana menyadarkan manusia supaya tidak lagi melakukan tindakan-tindakan yang menyebabkan menurunnya kualitas lingkungan hidup, dan dengan penuh kesadaran mereka berhenti melakukan perbuatan itu, kemudian berbalik melakukan perbuatan-perbuatan yang dapat melestarikan lingkungan sehingga ekosistem aman dan terjaga kelesatariannya. Banyak cara yang dapat dilakukan untuk memberikan pemahaman yang baik tentang lingkungan terhadap setiap individu, seperti penerangan, penyuluhan, bimbingan, dan pendidikan (formal dan non formal mulai dari TK, SD hingga perguruan tinggi) (Yafie, 2009: 50). Hamzah (2013: 43) menjelaskan bahwa " lingkungan hidup merupakan wujud sikap mental individu yang direfleksikan dalam perilakunya".

Ada 10 sifat karakter atau nilai-nilai Nilai Muwashafat yang perlu ditanamkan pada individu seseorang, yaitu, Salimul 'Aqīdah (Aqidah yang bersih), Shahīhul 'Ibādah (Ibadah yang benar), Matīnul Khuluq (Akhlak yang kokoh), Qowiyyul Jismi (kuat jasmani), Mutsaqqoful Fikri (Intelek dalam berpikir), Mujāhadatul Linafsihi (Berjuang Melawan hawa nafsu), Harisun 'Ala Waqtihi (Pandai menjaga waktu), Munazzamun fi Syu'unihi (Teratur dalam urusan), Qodirun 'Alal Kasbi (Mampu berusaha sendiri atau mandiri), Nafi'un Ligoirihi (Bermanfa'at bagi orang lain). 
Pendidikan karakter merupakan langkah sangat penting dan strategis dalam membangun kembali jati diri bangsa dan menggalang pembentukan masyarakat Indonesia baru. Pendekatan dalam penelitian ini adalah studi kepustakaan. Hasil kajian ini menunjukkan bahwa membentuk siswa yang berkarakter bukan suatu usaha mudah dan cepat. Hal itu memerlukan usaha terus menerus dan refleksi mendalam untuk membuat rentetan (Moral Choice) keputusan moral yang harus ditindaklanjuti dengan aksi nyata, sehingga menjadi hal yang praktis dan reflektif. Diperlukan sejumlah waktu untuk membuat semua itu menjadi (custom) kebiasaan dan membentuk watak atau tabiat seseorang. Karakter pendidikan harus melibatkan berbagai pihak, di keluarga dan rumah tangga, lingkungan sekolah, dan masyarakat.

\section{METODE PENELITIAN}

Penelitian ini merupakan penelitian lapangan (field research) yang bersifat kuantitatif, yaitu penelitian yang menggunakan angka dalam menyajikan data dan analisis yang menggunakan uji statistika. Penelitian kuantitatif merupakan penelitian yang dipandu oleh hipotesis tertentu, yang salah satu tujuan dari penelitian yang dilakukan adalah menguji hipotesis yang ditentukan sebelumnya (Saebani, 2008: 121).

Adapun Subjek penelitian ini adalah Guru di Sekolah Dasar Islam Terpadu Bunayya Pekanbaru yang berjumlah 45 orang. Sedangkan yang menjadi objek dalam penelitian ini adalah Murid Sekolah Dasar Islam Terpadu Bunayya Pekanbaru yang berjumlah 515 orang.

\section{Salīmul 'Aqīdah (Aqidah yang bersih)}

\begin{tabular}{|c|c|c|c|c|c|c|c|c|}
\hline \multirow[t]{2}{*}{ No. } & \multirow[t]{2}{*}{ Pernyataan } & \multicolumn{5}{|c|}{$\begin{array}{c}\text { Prosentasi (\%) } \\
\text { Frekwensi (f) }\end{array}$} & \multirow[t]{2}{*}{ Mean } & \multirow[t]{2}{*}{ Ket } \\
\hline & & STS & TS & KS & $\mathbf{S}$ & SS & & \\
\hline 1. & Murid paham aqidah yang benar & - & - & $\begin{array}{l}4.2 \\
(2)\end{array}$ & $\begin{array}{l}41.7 \\
(20)\end{array}$ & $\begin{array}{l}47.9 \\
(23)\end{array}$ & 4.47 & \\
\hline 2. & Murid memiliki perbedaan paham aqidah & $\begin{array}{l}25.0 \\
(12)\end{array}$ & $\begin{array}{l}16.7 \\
(8)\end{array}$ & $\begin{array}{c}12.5 \\
(6)\end{array}$ & $\begin{array}{c}14.6 \\
(7)\end{array}$ & $\begin{array}{l}25.0 \\
(12)\end{array}$ & 2.98 & \\
\hline
\end{tabular}




\begin{tabular}{|c|l|c|c|c|c|c|c|c|}
\hline 3. & Murid belajar dasar-dasar aqidah & - & - & - & $\begin{array}{l}31.3 \\
(15)\end{array}$ & $\begin{array}{c}62.5 \\
(30)\end{array}$ & 4.67 & \\
\hline 4. & Murid memiliki buku ajar aqidah khusus & - & - & 2.1 & 39.6 & 52.1 & 4.53 & \\
& anak & & & $(1)$ & $(19)$ & $(25)$ & & \\
\hline 5. & Murid belajar aqidah setiap hari & - & 2.1 & 4.2 & 29.2 & 58.3 & 4.53 & \\
& & & $(1)$ & $(2)$ & $(14)$ & $(28)$ & & \\
\hline
\end{tabular}

Berdasarkan tabel di atas maka berdasarkan aspek Salimul Aqidah kebanyakan guru-guru setuju (41.7\%) dan sangat setuju (47.9\%) bahwa muridmurid faham akan aqidah yang benar. Kebanyakan guru (36 orang) tidak setuju bahwa murid-murid memiliki perbedaan aqidah. Semua guru setuju (31.3\%) dan sangat setuju (62.5\%) bahwa murid- murid belajar dasar-dasar aqidah. Mayoritas guru (44 orang) juga menyatakan bahwa murid memiliki buku ajar aqidah khusus anak, dan hanya satu orang guru saja yang menyatakan kurang setuju. Begitu juga mayoritas guru (42 orang) menyatakan bahwa murid senantiasa belajar aqidah setiap hari.

\section{Shahihul 'Ibadah (Ibadah yang benar)}

\begin{tabular}{|c|c|c|c|c|c|c|c|c|}
\hline \multirow[t]{2}{*}{ No. } & \multirow[t]{2}{*}{ Pernyataan } & \multicolumn{5}{|c|}{$\begin{array}{l}\text { Prosentasi (\%) } \\
\text { Frekwensi (f) }\end{array}$} & \multirow[t]{2}{*}{ Mean } & \multirow[t]{2}{*}{ Ket } \\
\hline & & STS & TS & KS & $S$ & SS & & \\
\hline 1. & $\begin{array}{l}\text { Murid memahami tuntunan wudhu' yang } \\
\text { benar }\end{array}$ & - & - & 2.1 & $\begin{array}{c}18.8 \\
(9)\end{array}$ & $\begin{array}{l}72.9 \\
(35)\end{array}$ & 4.76 & \\
\hline 2. & Murid memahami tuntunan shalat yang benar & - & - & $\begin{array}{l}2.1 \\
(1)\end{array}$ & $\begin{array}{l}29.2 \\
(14)\end{array}$ & $\begin{array}{l}66.7 \\
(30)\end{array}$ & 4.64 & \\
\hline 3. & $\begin{array}{l}\text { Murid melakukan shalat berjamaah di } \\
\text { sekolah }\end{array}$ & - & - & - & $\begin{array}{c}16.7 \\
(8)\end{array}$ & $\begin{array}{l}77.1 \\
(37) \\
\end{array}$ & 4.82 & \\
\hline 4. & $\begin{array}{l}\text { Murid melakukan dhuha, zhuhur, dan ashar } \\
\text { berjamaah }\end{array}$ & - & - & - & $\begin{array}{l}18.8 \\
(9)\end{array}$ & $\begin{array}{l}75.0 \\
(36)\end{array}$ & 4.80 & \\
\hline 5. & $\begin{array}{l}\text { Murid paham dan menerapkan shalat } \\
\text { berjamaah di sekolah dan rumah }\end{array}$ & - & - & $\begin{array}{l}6.3 \\
(3)\end{array}$ & $\begin{array}{l}33.3 \\
(16)\end{array}$ & $\begin{array}{l}54.2 \\
(26)\end{array}$ & 4.51 & \\
\hline
\end{tabular}

Berdasarkan aspek Shahihul Ibadah tabel di atas menunjukkan para guru menyatakan bahwa ibadah para murid sudah baik; dari segi pemahaman mengenai tuntunan wudhu. Shalat yang benar, melakukan solat berjamaah di sekolah secara berjamaah, dan dari segi kefahaman mereka tentang urgensitas pelaksanaan solat berjamaah di sekolah dan rumah.

Matinul Khuluq (Akhlak yang kokoh)

\begin{tabular}{|c|l|c|c|c|c|c|c|c|}
\hline No. & \multicolumn{1}{|c|}{ Pernyataan } & \multicolumn{4}{|c|}{ Prosentasi (\%) } & \multirow{3}{*}{ Mean } & \multirow{2}{*}{ Ket } \\
& & STS & TS & KS & S & SS & & \\
\hline & & - & - & 2.1 & 45.8 & 45.8 & 4.47 & \\
1. & Murid memiliki sifat jujur & & & $(1)$ & $(22)$ & $(22)$ & & \\
\hline 2. & Murid menerapkan sabar ketika bergaul & - & - & 6.3 & 45.8 & 41.7 & 4.38 & \\
& & & & $(3)$ & $(22)$ & $(20)$ & & \\
\hline 3. & Murid mengikuti aturan sekolah yang & - & - & - & 52.1 & 41.7 & 4.44 & \\
& ditetapkan & & & & $(25)$ & $(20)$ & & \\
\hline 4. & Murid amanah dalam mengerjakan tugas & - & - & 4.2 & 54.2 & 35.4 & 4.33 & \\
& & & & $(2)$ & $(26)$ & $(17)$ & & \\
\hline 5. & Murid paham akhlak Al-Quran seperti & - & - & 6.3 & 41.7 & 45.8 & 4.42 & \\
& Rasulullah Shallahu Alaihi wa Sallam & & & $(3)$ & $(20)$ & $(45)$ & & \\
\hline
\end{tabular}


Tabel ini menggambarkan tentang aspek matinul khuluk pada siswa. Dari lima indikator aspek ini hanya beberapa orang responden saja yang kurang setuju dengan pernyataan yang telah disebutkan, sementara mayoritas responden setuju dan sangat setuju bahwa murid memiliki sikap jujur (44 orang), murid menerapkan sabar ketika bergaul (42 orang), murid mengikuti aturan sekolah yang ditetapkan (45 orang), murid amanah dalam mengerjakan tugas (43 orang), murid paham akhlak Al-Quran seperti Rasulullah Shallahu 'Alaihi wa Sallam.

Qowiyyul Jismi (kuat jasmani)

\begin{tabular}{|c|c|c|c|c|c|c|c|c|}
\hline \multirow[t]{2}{*}{ No. } & \multirow[t]{2}{*}{ Pernyataan } & \multicolumn{5}{|c|}{$\begin{array}{c}\text { Prosentasi (\%) } \\
\text { Frekwensi (f) }\end{array}$} & \multirow[t]{2}{*}{ Mean } & \multirow[t]{2}{*}{ Ket } \\
\hline & & STS & TS & KS & S & SS & & \\
\hline 1. & Murid melakukan program senam sehat & - & - & - & $\begin{array}{l}31.3 \\
(15)\end{array}$ & $\begin{array}{l}62.5 \\
(30)\end{array}$ & 4.67 & \\
\hline 2. & $\begin{array}{l}\text { Murid mengikuti pelajaran olahraga } \\
\text { setiap } \\
\text { Minggu }\end{array}$ & - & $\begin{array}{l}2.1 \\
(1)\end{array}$ & - & $\begin{array}{l}31.3 \\
(15)\end{array}$ & $\begin{array}{l}60.4 \\
(29)\end{array}$ & 4.60 & \\
\hline 3. & Murid melakukan olahraga di lapangan & - & - & $\begin{array}{l}2.1 \\
(1)\end{array}$ & $\begin{array}{l}35.4 \\
(17)\end{array}$ & $\begin{array}{l}56.3 \\
(27)\end{array}$ & 4.58 & \\
\hline 4. & Murid berprestasi di bidang olahraga & - & - & $\begin{array}{l}4.2 \\
(2)\end{array}$ & $\begin{array}{l}56.3 \\
(27)\end{array}$ & $\begin{array}{l}33.3 \\
(16)\end{array}$ & 4.31 & \\
\hline
\end{tabular}

Tabel tersebut menggambarkan aspek Qowiyyul Jismi (kuat jasmani) pada siswa. Dari aspek ini nampak juga bahwa mayoritas responden menilai siswa sangat baik pada aspek ini. Semua responden menyatakan setuju dan sangat setuju murid melakukan program senam sehat
(31.3 \% dan 62.5\%), murid mengikuti pelajaran olahraga setiap minggu $(31.3 \%$ dan $60.4 \%$ ), murid melakukan olahraga di lapangan (35.4\% dan 56.3\%) serta murid berprestasi di bidang olahraga (56.3\% dan $33.3 \%)$.

\section{Mutsaqqoful Fikri (Intelek dalam berpikir)}

\begin{tabular}{|c|l|c|c|c|c|c|c|c|}
\hline No. & \multicolumn{1}{|c|}{ Pernyataan } & \multicolumn{4}{|c|}{ Prosentasi (\%) } & \multirow{3}{*}{ Frekwensi (f) } & \multirow{2}{*}{ Mean } & Ket \\
& & STS & TS & KS & S & SS & & \\
\hline 1. & Murid peka terhadap lingkungannya & - & - & 4.2 & 50 & 37.5 & 4.36 & \\
& & & & $(2)$ & $(24)$ & $(18)$ & & \\
\hline 2. & Murid mendapat tugas-tugas nalar & - & - & 14.6 & 50.0 & 29.2 & 4.16 & \\
& & & & $(7)$ & $(24)$ & $(14)$ & & \\
\hline 3. & Murid memiliki rata-rata daya pikir yang & - & - & $\begin{array}{l}14.6 \\
(26.3\end{array}$ & 22.9 & 4.09 & \\
& kuat & & & $((7)$ & $(27)$ & $(11)$ & & \\
\hline 4. & Murid selalu belajar berpikir terhadap & - & - & 12.5 & 56.3 & 25.0 & 4.13 & \\
& apa yang di sekitarnya & & & $(6)$ & $(27)$ & $(12)$ & & \\
\hline
\end{tabular}

Dari tabel ini dapat diketahui ratarata responden memberikan tanggapan yang positif terhadap aspek ini. Dalam item Murid peka terhadap lingkungannya 24 orang responden (50\%) guru setuju dan $37.5 \%$ sangat setuju. Hanya 7 orang responden saja (14.6\%) yang kurang setuju dengan item murid mendapat tugas-tugas nalar, begitu juga dari segi murid memiliki rata-rata daya pikir yang kuat $56.3 \%$ setuju dan $22.9 \%$ sangat setuju. Sedang item Murid selalu belajar berpikir terhadap apa yang di sekitarnya mendapat tanggapan $56.3 \%$ setuju dan $25.0 \%$ sangat setuju. 
Mujahadatul Linafsihi (Berjuang Melawan hawa nafsu)

\begin{tabular}{|c|l|c|c|c|c|c|c|c|}
\hline No. & \multicolumn{1}{|c|}{ Pernyataan } & \multicolumn{4}{|c|}{ Prosentasi (\%) } & \multirow{3}{*}{ Mean } & \multirow{2}{*}{ Ket } \\
& & STS & TS & KS & S & SS & & \\
\hline & & - & 4.2 & 20.8 & 41.7 & 27.1 & 3.98 & \\
\hline 1. & Murid melakukan puasa senin kamis & & $(2)$ & $(10)$ & $(20)$ & $(13)$ & & \\
\hline 2. & Murid terbiasa puasa dalam setiap pecan & - & 2.1 & 18.8 & 45.8 & 27.1 & 4.04 & \\
& & & $(1)$ & $(9)$ & $(22)$ & $(13)$ & & \\
\hline 3. & Murid paham arti pentingnya melawan & - & 4.2 & 8.3 & 43.8 & 37.5 & 4.22 & \\
& hawa Nafsu & & $(2)$ & $(4)$ & $(21)$ & $(18)$ & & \\
\hline 4. & Murid mengikuti kajian tazkiyatunnufus & - & 6.3 & 8.3 & 60.4 & 18.8 & 3.98 & \\
& di Sekolah & & $(3)$ & $(4)$ & $(29)$ & $(9)$ & & \\
\hline 5. & Murid steril dari pembauran masyarakat & 4.2 & 4.2 & 14.6 & 52.1 & 18.8 & 3.82 & \\
& umum (lingkungan luar sekolah) & $(2)$ & $(2)$ & $(7)$ & $(25)$ & $(9)$ & & \\
\hline
\end{tabular}

Tabel ini menunjukkan aspek Mujahadatul Linafsihi (Berjuang Melawan hawa nafsu) berada pada tahap baik, karena kebanyakan responden menyatakan setuju dan sangat setuju dengan item pernyataan yang berkenaan dengan aspek ini.

Harishun 'Ala Waqtihi (Pandai menjaga waktu)

\begin{tabular}{|c|c|c|c|c|c|c|c|c|}
\hline \multirow[t]{2}{*}{ No. } & \multirow[t]{2}{*}{ Pernyataan } & \multicolumn{5}{|c|}{$\begin{array}{l}\text { Prosentasi (\%) } \\
\text { Frekwensi (f) }\end{array}$} & \multirow[t]{2}{*}{ Mean } & \multirow[t]{2}{*}{ Ket } \\
\hline & & STS & TS & KS & $\mathbf{S}$ & SS & & \\
\hline 1. & Murid selalu on time masuk sekolah & - & $\begin{array}{l}4.2 \\
(2)\end{array}$ & $\begin{array}{l}6.3 \\
(3)\end{array}$ & $\begin{array}{l}45.8 \\
(22)\end{array}$ & $\begin{array}{l}37.5 \\
(18)\end{array}$ & 4.24 & \\
\hline 2. & Murid selalu mengerjakan PR di rumah & $\begin{array}{l}2.1 \\
(1)\end{array}$ & - & $\begin{array}{c}10.4 \\
(5)\end{array}$ & $\begin{array}{l}54.2 \\
(26)\end{array}$ & $\begin{array}{l}27.1 \\
(13)\end{array}$ & 4.11 & \\
\hline 3. & Murid diajar disiplin setiap hari & - & $\begin{array}{l}2.1 \\
(1)\end{array}$ & $\begin{array}{l}6.3 \\
(3)\end{array}$ & $\begin{array}{l}33.3 \\
(16)\end{array}$ & $\begin{array}{l}52.1 \\
(25)\end{array}$ & 4.44 & \\
\hline 4. & $\begin{array}{l}\text { Murid patuh dan tunduk terhadap } \\
\text { kegiatan kelas }\end{array}$ & - & - & $\begin{array}{l}2.1 \\
(1)\end{array}$ & $\begin{array}{l}39.6 \\
(19)\end{array}$ & $\begin{array}{l}52.1 \\
(25)\end{array}$ & 4.53 & \\
\hline 5. & Murid rajin belajar setiap waktu & - & - & $\begin{array}{l}4.2 \\
(2)\end{array}$ & $\begin{array}{l}47.9 \\
(23)\end{array}$ & $\begin{array}{l}41.7 \\
(20)\end{array}$ & 4.40 & \\
\hline
\end{tabular}

Pada aspek Harishun 'Ala Waqtihi (Pandai menjaga waktu) mayoritas responden (45.8\%) menyatakan setuju bahwa murid selalu on time masuk sekolah, 54.2\% mereka menyatakan bahwa murid selalu mengerjakan PR di
41.7\% responden setuju bahwa murid terbiasa melakukan puasa senin kamis, 45.8\% mereka menyatakan bahwa murid sudah terbiasa melakukan puasa setiap pekan, sementara $43.8 \%$ responden meyatakan setuju bahwa murid sudah faham pentingnya melawan hawa nafsu.

Munazhzhamun fi Syu'unihi (Teratur dalam urusan)

\begin{tabular}{|c|c|c|c|c|c|c|c|c|}
\hline \multirow[t]{2}{*}{ No. } & \multirow[t]{2}{*}{ Pernyataan } & \multicolumn{5}{|c|}{$\begin{array}{c}\text { Prosentasi (\%) } \\
\text { Frekwensi (f) }\end{array}$} & \multirow[t]{2}{*}{ Mean } & \multirow{2}{*}{ Ket } \\
\hline & & STS & TS & KS & $\mathbf{S}$ & SS & & \\
\hline 1. & Murid belajar tertib dan tepat & - & - & $\begin{array}{l}2.1 \\
(1)\end{array}$ & $\begin{array}{l}54.2 \\
(26)\end{array}$ & $\begin{array}{l}37.5 \\
(18)\end{array}$ & 4.38 & \\
\hline
\end{tabular}




\begin{tabular}{|c|l|c|c|c|c|c|c|c|}
\hline 2. & Murid mengelola kelas rapi dan indah & - & - & $\begin{array}{l}4.2 \\
(2)\end{array}$ & $\begin{array}{l}45.8 \\
(22)\end{array}$ & $\begin{array}{l}43.8 \\
(21)\end{array}$ & 4.42 & \\
\hline 3. & Murid melakukan piket kelas & - & - & 2.1 & 50.0 & 41.7 & 4.42 & \\
& & & & $(1)$ & $(24)$ & $(20)$ & & \\
\hline 4. & Murid berkegiatan terprogram & - & - & 4.2 & 50.0 & 39.6 & 4.38 & \\
& & & & $(2)$ & $(24)$ & $(19)$ & & \\
\hline 5. & Murid menerima sistem satu arah dan & - & - & 8.3 & 41.7 & 43.8 & 4.38 & \\
& bertarget & & & $(4)$ & $(20)$ & $(21)$ & & \\
\hline
\end{tabular}

Dari tabel ini dapat diketahui juga yaitu tentang munazhzhamun fi Syu'unihi (Teratur dalam urusan) bahwa responden rata-rata setuju dengan semua item yang dinyatakan dalam aspek ini. Artinya murid sudah baik dalam aspek ini. Tidak ada seorangpun dari responden yang menyakan tidak setuju dengan pernyataan pada aspek ini diantaranya yang menyatakan setuju seperti pada item murid belajar tertib dan tepat 26 orang setuju (54.2\%), Murid mengelola kelas rapi dan indah menyatakan setuju sebanyak 21 orang (45.8\%) dan Murid melakukan piket kelas yang menjawab kurang setuju (2.1\%) artinya lebih banyak yang menyatakan setuju. Hal ini menunjukkan bahwa murid sudah teratur dalam melaksana tugas dan kewajiban sekolahnya.

Qodirun 'Alal Kasbi (Mampu berusaha sendiri atau mandiri)

\begin{tabular}{|c|c|c|c|c|c|c|c|c|}
\hline \multirow[t]{2}{*}{ No. } & \multirow[t]{2}{*}{ Pernyataan } & \multicolumn{5}{|c|}{$\begin{array}{c}\text { Prosentasi (\%) } \\
\text { Frekwensi (f) }\end{array}$} & \multirow[t]{2}{*}{ Mean } & \multirow[t]{2}{*}{ Ket } \\
\hline & & STS & TS & $\mathbf{K S}$ & $\mathbf{S}$ & SS & & \\
\hline 1. & $\begin{array}{l}\text { Murid datang dan pulang sendiri ke } \\
\text { sekolah }\end{array}$ & $\begin{array}{l}4.2 \\
(2)\end{array}$ & $\begin{array}{c}16.7 \\
(8)\end{array}$ & $\begin{array}{l}20.8 \\
(10)\end{array}$ & $\begin{array}{l}25.0 \\
(12)\end{array}$ & $\begin{array}{l}27.1 \\
(13)\end{array}$ & 3.58 & \\
\hline 2. & $\begin{array}{l}\text { Murid melakukan aktivitasnya lebih } \\
\text { banyak dengan bantuan }\end{array}$ & - & $\begin{array}{l}12.5 \\
(6)\end{array}$ & $\begin{array}{l}25.0 \\
(12)\end{array}$ & $\begin{array}{l}43.8 \\
(21)\end{array}$ & $\begin{array}{c}12.5 \\
(6)\end{array}$ & 3.60 & \\
\hline 3. & Murid mengerti watak temannya & $\begin{array}{l}2.1 \\
(2)\end{array}$ & $\begin{array}{c}12.5 \\
(6)\end{array}$ & $\begin{array}{c}18.8 \\
(9)\end{array}$ & $\begin{array}{l}37.5 \\
(18)\end{array}$ & $\begin{array}{l}22.9 \\
(11)\end{array}$ & 3.71 & \\
\hline 4. & Murid mendapat reward secara mandiri & - & $\begin{array}{c}12.5 \\
(6)\end{array}$ & $\begin{array}{l}8.3 \\
(4)\end{array}$ & $\begin{array}{l}45.8 \\
(22)\end{array}$ & $\begin{array}{l}27.1 \\
(13)\end{array}$ & 3.93 & \\
\hline 5. & Murid belajar mandiri & - & $\begin{array}{l}4.2 \\
(2)\end{array}$ & $\begin{array}{l}4.2 \\
(2)\end{array}$ & $\begin{array}{l}45.8 \\
(22)\end{array}$ & $\begin{array}{l}39.6 \\
(19)\end{array}$ & 4.29 & \\
\hline
\end{tabular}

Tabel ini menggambarkan kepada kita aspek Qodirun 'Alal Kasbi (Mampu berusaha sendiri atau mandiri), dari hasil analisis dapat diketahui bahwa responden memberikan penilaian bahwasanya murid mampu berusaha sendiri dan mandiri, walau dalam beberapa pernyataan banyak juga responden yang menyatakan kurang setuju,seperti pada item Murid datang dan pulang sendiri ke sekolah, 10 orang kurang setuju (20.8\%), 25.0\% murid melakukan aktivitas lebih banyak dengan bantuan, $18.8 \%$ kurang setuju bahwa murid dapat mengerti watak temannya.

Nafi'un Lighoirihi (Bermanfa'at bagi orang lain)

\begin{tabular}{|c|c|c|c|c|c|c|c|c|}
\hline \multirow[t]{2}{*}{ No. } & \multirow[t]{2}{*}{ Pernyataan } & \multicolumn{5}{|c|}{$\begin{array}{l}\text { Prosentasi (\%) } \\
\text { Frekwensi (f) }\end{array}$} & \multirow[t]{2}{*}{ Mean } & \multirow[t]{2}{*}{ Ket } \\
\hline & & STS & TS & KS & S & SS & & \\
\hline 1. & $\begin{array}{l}\text { Murid memiliki tradisi membantu dan } \\
\text { Menolong }\end{array}$ & - & $\begin{array}{l}2.1 \\
(1)\end{array}$ & $\begin{array}{l}6.3 \\
(3)\end{array}$ & $\begin{array}{l}39.6 \\
(19)\end{array}$ & $\begin{array}{l}45.8 \\
(22)\end{array}$ & 4.38 & \\
\hline
\end{tabular}




\begin{tabular}{|c|l|c|c|c|c|c|c|c|}
\hline 2. & $\begin{array}{l}\text { Murid melakukan program ayo sedekah } \\
\text { setiap } \\
\text { pekan (missal setiap jum'at) }\end{array}$ & - & $\begin{array}{l}2.1 \\
(1)\end{array}$ & $\begin{array}{l}2.1 \\
(1)\end{array}$ & $\begin{array}{l}31.3 \\
(15)\end{array}$ & $\begin{array}{l}58.3 \\
(28)\end{array}$ & 4.56 & \\
\hline 3. & $\begin{array}{l}\text { Murid mengikuti program bantuan sosial } \\
\text { setiap bulan }\end{array}$ & - & 2.1 & 4.2 & 35.4 & 52.1 & 4.47 & \\
$(1)$ & $(2)$ & $(17)$ & $(25)$ & & \\
\hline 4. & $\begin{array}{l}\text { Murid menerapkan tradisi sharing ilmu } \\
\text { misal belajar berceramah agama di kelas }\end{array}$ & - & - & 2.1 & 45.8 & 45.8 & 4.47 & \\
\hline 5. & $\begin{array}{l}\text { Murid melakukan program makan } \\
\text { bersama setiap semester }\end{array}$ & - & 2.1 & 8.3 & 22.9 & 60.4 & 4.51 & \\
$(22)$ & $(4)$ & $(11)$ & $(29)$ & & \\
\hline
\end{tabular}

Dari segi aspek Nafi'un Lighoirihi (Bermanfa'at bagi orang lain), mayoritas responden menyatakan setuju dan sangat setuju bahwa murid-murid dapat memberikan manfaat bagi orang lain, hal ini tercermin dari pernyataan mereka misalnya dalam item Murid memiliki tradisi membantu dan menolong setuju $39.6 \%$ dan sangat setuju $45.8 \%$, murid mengikuti program bantuan sosial setiap bulan yang setuju 17 orang (35.4\%) dan yang sangat setuju sebanyak 52.1\% (25 orang).

Penjabaran hasil analisa pendidikan karakter berbasis nilai muwashafat pada murid sekolah dasar Islam terpadu Bunayya Pekanbaru memiliki pengaruh yang singnifikan dalam membentuk karakternya.

\section{PENUTUP}

Berdasarkan hasil analisis data dan hasil wawancara serta obsevasi maka menyimpulkan bahwa: Pendidikan Karakter Murid di Sekolah Dasar Islam Terpadu Al-Bunayya Pekanbaru yaitu berbasis Nilai Muwashafat terlihat pada analisa statistik yang diuraikan pada table 10 muwashafat yang mempengaruhi secara signikan terhadap karakter murid.

Perlunya konsisten guru untuk memelihara dan menjaga nilai-nilai muwashafat dalam pendidikan karakter murid sekolah dasar Islam terpadu Bunayya Pekanbaru.[]

\section{DAFTAR REFERENSI}

Adisusilo, Sutarjo. Pembelajaran Nilai Karakter. Jakarta: PT. Raja Grafino Persada, 2012.

Aeni, Ani Nur. "Pendidikan Karakter Untuk Siswa SD Dalam Perspektif Islam." Mimbar Sekolah Dasar 1.1 (2014): 50-58.

Ainiyah, Nur. "Pembentukan Karakter Melalui Pendidikan Agama Islam." Al-Ulum 13.1 (2013): 25-38.

Al-Banna, Hasan Majmu'atu Rasail Hasan Al-Banna. (Kumpulan Risalah Dakwah Hasan Al-Banna) Jilid 2. Penerjemah, Khozin Abu Faqih, Jakarta: Al-I'tishom Cahaya Umat, 2006.

Faturrohman, Pupuh, Pengembangan Pendidikan Karakter, Bandung: PT Refika Aditama, 2013.

Gunawan, Heri. Pendidikan Karakter Konsep dan Implementasi. Bandung: PT Alfabet, 2014.

Hakim, Rosniati. "Pembentukan karakter peserta didik melalui pendidikan berbasis Al-Quran." Jurnal Pendidikan Karakter 4.2 (2014).

Kurniawan, Syamsul. Pendidikan Karakter, Yogyakarta: Ar- Ruzz Media, 2016.

Mu'in, Fatchul. Pendidikan Karakter konstrusi Teoretik \& Praktik, Jogjakarta: Ar-Ruzz Media, 2016.

Mukminin, Amirul. "Strategi Pembentukan Karakter Peduli Lingkungan di Sekolah Adiwiyata Mandiri." Ta'dib: Journal of Islamic Education (Jurnal Pendidikan Islam) 19.02 (2014): 227-252. 
Muslich, Masnur. Pendidikan Karakter Menjawab Tantangan Krisis Multidimensional. Jakarta: PT Bumi Aksara, 2011.

Nasir, Haidar. Pendidikan Karakter berbasis Agama dan Kebudayaan. Yogykarta: Multi Presindo, 2013.

Nata, Abuddin. Karakter Mulia Edisi Revisi, Jakarta: Raja Grafinda Persada, 2013.

Samani, Muchlas. Konsep dan Model Pendidikan Karakter. Bandung: PT Remaja Rosdakarya, 2011.

Subianto, Jito. "Peran keluarga, sekolah, dan masyarakat dalam pembentukan karakter berkualitas." Edukasia: Jurnal Penelitian Pendidikan Islam 8.2 (2013).

Sulistyowati, Endah. Implementasi Kurikulum Pendidikan Karakter, Yogyakarta: PT Citra Aji Parama, 2012.

Sutiyono, Sutiyono. "Penerapan Pendidikan Budi Pekerti Sebagai Pembentukan Karakter Siswa Di Sekolah: Sebuah Fenomena Dan Realitas." Jurnal Pendidikan Karakter 3.3 (2013). 309-320.

Syafe'i, Imam. "Pondok pesantren: Lembaga pendidikan pembentukan karakter." Al-Tadzkiyyah: Jurnal Pendidikan Islam 8.1 (2017): 61-82. 